УДК 004.056.2

\author{
О. Я. Матов ${ }^{1}$, В. С. Васименко ${ }^{2}$ \\ ${ }^{1}$ Інститут проблем реєстрації інформації НАН України \\ вул. М. Шпака, 2, 03113 Київ, Україна \\ ${ }^{2}$ Національний авіаційний університет \\ вул. Космонавта Комарова, 1, 03058 Київ, Україна
}

\title{
Процедура нулізації при контролі та поновленні цілісності інформаційних об'єктів у коді умовних Аишків
}

Запропоновано швидкодіючі прочедури контролю ичілісності та корегування спотворень інформаційних об'єктів телекомунікаційних мереж на основі алгоритму нулізації в умовах застосування коду умовних лишків.

Ключові слова: завадостійке кодування, код умовних лишків, контроль иілісності, контрольна основа, основа коду, поновлення иілісності, спотворення.

\section{Вступ}

Разом із задачею забезпечення цілісності інформаційних об'єктів у сучасних телекомунікаціях не менш важливою $є$ задача забезпечення доступності цих об'єктів. 3 цією метою прагнуть підвищувати швидкість інформаційного обміну при збереженні можливостей щодо цілісності. Однією із можливостей цього є застосування багаторівневих (багатопозиційних) символів. Однак при цьому спотворення одного із символів призводить до появи групового (наприклад, у декількох бітах) спотворення (спотворення узагальненого символу). Для виявлення таких спотворень доцільно застосовувати спеціальні коди для виявлення і (можливого) виправлення спотворень в узагальнених символах. Одним із таких кодів $\epsilon$ код умовних лишків (ЛУ-код) $[1,2,4]$. У таких кодах відповідний інформаційний об'єкт розглядається як деяке число, яке за певними правилами розподіляється на декілька, наприклад на $n$ груп, двійкових розрядів. Ці групи, у свою чергу, розглядаються як залишки $a_{i}$ від ділення деякого умовного числа в позиційній системі числення $A$ на набір умовних основ $p_{i}(i=1,2, \ldots, n)$ :

$$
A=a_{1}, a_{2}, \ldots, a_{n} .
$$


Для забезпечення функцій контролю, а, можливо, контролю та поновлення цілісності до складу основ додають додаткові (одну чи, в загальному випадку, декілька) контрольні, надлишкові основи системи числення, наприклад $p_{q}$, та обраховують (на етапі кодування) лишок по контрольній основі (якщо контрольна основа одна) $a_{q}$.

Відомі алгоритми кодування-декодування в таких кодах. Одним із таких алгоритмів $\epsilon$, так званий, $z$-алгоритм. Його перевагю $\epsilon$ відносна простота суто алгебраїчних процедур, але суттєвим недоліком - застосування у цих процедурах операції обчислення цілої частини від нескінчених дробових чисел, що може стати причиною неправильного кодування-декодування. Іншим є алгоритм нулізації, який не має операцій над нескінченими дробовими числами, але у відомих описах і реалізаціях цей алгоритм використовується лише для виявлення факту наявності спотворень [3], або ж для реалізації потребує великої кількості операцій, а відтак, і значних часових витрат [4].

Метою цієї роботи є розроблення процедури застосування алгоритму нулізації не лише в режимі виявлення, а й у режимі швидкодійного корегування спотворень.

\section{Використання амгоритму нумізації Аля виявмення та корегування спотворень}

Як відомо [3], внаслідок декодування із застосуванням процедури нулізації отримується величина, яка має лишки по всім основам, окрім контрольної, що дорівнюють нулю, а по контрольній - лишок, величина якого

$$
\gamma=(k P) \bmod p_{q}
$$

де $k=0,1,2, \ldots, p_{q}-1$. Для неспотворених чисел, тобто при $\gamma=0$, величина $k=0$, для спотворених $\gamma \neq 0$. Отже, визначений алгоритм надає змогу виявлення факту наявності спотворень.

Звернемо увагу, що з останнього виразу нескладно визначити номер піддіапазону $k$, до якого попадає спотворене число $A$ :

$$
k=(\gamma / P) \bmod p_{q} .
$$

Проілюструємо сказане на прикладах кодування-декодування із застосуванням у ЛУ-коді процедур нулізації, що буде корисним і при подальших міркуваннях.

Приклад 1. Нехай необхідно закодувати з використанням алгоритму нулізації вихідний код 110110, вважаючи, що довжина узагальненого символу, а отже і можлива довжина пакету спотворень $b=2$. Тоді можливе розбиття вихідного коду на три $(n=3)$ дворозрядні групи $\alpha_{1}=11_{2}, \alpha_{2}=01_{2}, \alpha_{3}=10_{2}, s=4$, а як умовні основи можна вибрати $p_{1}=4, p_{2}=5, p_{3}=7$. При цьому як значення контрольної основи можна вибрати $p_{q}=71$ (нагадаємо, що контрольна основа повинна задовольняти умові $\left.p_{q}>2 \cdot p_{n} \cdot p_{n-1}=2 \cdot 5 \cdot 7=70\right)$, що потребує для свого відображення семи розрядів. Унаслідок цього для кодування формується код 


$$
A=11.01 .10 .0000000
$$

Перше мінімальне число $t_{1}$ повинно мати лишок по першій основі, що дорівнює $11_{(2)}=3_{(10)}$. Таким числом є $t_{1}=3$ або при представленні в ЛУ-коді з вибраними основами

$$
t_{1}=11.11 .011 .0000011
$$

Друге мінімальне число $t_{2}$ повинно мати лишок по першій основі, який дорівнює нулю, а по другій

$$
\left(\left(\alpha_{2}-\alpha_{2}^{1}\right)\left(\bmod p_{2}\right)=(1-3)(\bmod 5)=11_{(2)}\right.
$$

Мінімальним числом, яке має такі лишки по першій i другій основам, є $t_{2}=8$, тобто

$$
t_{2}=00.11 .001 .0001000 \text {. }
$$

Трете мінімальне число $t_{3}$ повинно мати нульові лишки по першим двом основам, а по третій

$$
\left(\left(\alpha_{3}-\alpha_{3}^{1}-\alpha_{3}^{2}\right)\left(\bmod p_{3}\right)=(2-3-1)(\bmod 7)=5=101_{(2)}\right.
$$

Мінімальним числом, що має такі лишки, $є t_{3}=40$, тобто

$$
t_{3}=00.00 .101 .0101000 \text {. }
$$

Тоді сума цих чисел $T=\sum_{i=1}^{3} t_{i}$ дорівнює 51 , тобто

$$
T=11.01 .10 .0110011
$$

Код T= Ає результатом кодування.

Приклад 2. Необхідно декодувати з використанням алгоритму нулізації базове кодове слово $\tilde{A}=11.01 .01 .0110011$, в якому спотворена третя пара розрядів при спотворенні первинного значення коду третьої групи 10 на величину 110 так, що $(10-110) \bmod 7=01$. Як і раніше (приклад 1$)$ :

$$
\begin{aligned}
& t_{1}=11.11 .011 .0000011, \\
& t_{2}=00.11 .001 .0001000 .
\end{aligned}
$$

Для третього мінімального числа $t_{3}$

$$
\left(\left(\alpha_{3}-\alpha_{3}^{1}-\alpha_{3}^{2}\right)\left(\bmod p_{3}\right)=(1-3-1)(\bmod 7)=4=100_{(2)} .\right.
$$


Мінімальним числом, що має такі лишки, $є t_{3}=60$, тобто

$$
t_{3}=00.00 .100 .0111100 .
$$

При цьому

$$
T=\sum_{i=1}^{3} t_{i}=71
$$

але оскільки $T(\bmod 71)=71(\bmod 71)=0$, то $T=11.01 .01 .0000000$

$\mathrm{i} \quad \gamma=\left(\alpha_{q}-\left(\mathrm{T} \bmod p_{q}\right)\right)\left(\bmod p_{q}\right)=(0110011-0000000)(\bmod 71)=51$.

Оскільки $\gamma \neq 0$, то можна зробити висновок про наявність спотворення в числі, щуо декодується.

Для корегування спотворень за результатами нулізації слід визначити не лише факт наявності спотворень, але і їхнє місце та величину. Одним із можливих кроків на цьому шляху є визначення, до якого з інтервалів (піддіапазонів) величиною $Р$ потрапляє спотворене число.

Нагадаємо, що введення контрольної основи величиною $p_{q}$ призводить до розширення діапазону представлення $P$ в $p_{q}$ разів, іншими словами утворює $p_{q}$ піддіапазонів величиною $P$ кожен. Нагадаємо також [3], що спотворене число може бути представленим як сума початкового (не спотвореного) числа $A$ та вектора спотворень $E: \tilde{A}=A+E$, де $A=a_{1}, a_{2}, \ldots, a_{i}, \ldots a_{q}$ - вихідне (неспотворене) число, а вектор спотворення $E$ в СЛК має лишки, що дорівнюють нулю по усім основам, окрім тієї, де $\epsilon$ спотворення. Тоді вектор спотворення $\epsilon$ числом виду $E=0,0, \ldots, \Delta a_{i}, 0,0, \ldots, 0=l_{i} \cdot R_{i}$.

Тобто $E=0,0, \ldots,\left(l_{i} \cdot R_{i}\right) \bmod p_{i}, 0,0, \ldots, 0$, оскільки тільки числа, які діляться націло на $R_{i}=R / p_{i}$ мають у своєму представленні в системі лишкових класів (СЛК) такий набір лишків. У останніх виразах величина $R=\prod_{i=1}^{k=n+1} p_{i}-$ контрольний (повний) діапазон представлення чисел у СЛК, а лишок від спотворення $\Delta A_{i}$ у СЛК має вигляд $\Delta a_{i}=E \bmod p_{i}=\left(l_{i} \cdot R_{i}\right) \bmod p_{i}$. Тобто спотворене число $\widetilde{A}=A+E$, а спотворений лишок по основі $p_{i}$ має значення:

$$
\widetilde{a}_{i}=\widetilde{A} \bmod p_{i}=(A+E) \bmod p_{i}=\left(a_{i}+\Delta a_{i}\right) \bmod p_{i} .
$$

На числовій осі (див. рисунок) величина спотворення $l_{i} \cdot R_{i}$ відображається точкою в одному з піддіапазонів «контрольного» діапазону $[(P+1), R)$. Відповідно, процес спотворення початкового числа $A$ відобразиться переміщенням точки $A$ iз робочого діапазону $[0, P)$ до деякого піддіапазону з номером $k$, тобто до піддіапазону $[k \cdot P,(k \cdot P+1))$. Звернемо увагу на те, що, залежно від величини початкового чис- 
ла $A$ спотворене число $\left(A^{\prime}=l_{i} \cdot R_{i}+A_{1}\right.$ чи $\left.A^{\prime \prime}=l_{i} \cdot R_{i}+A_{2}\right)$, може попасти до діапазону 3 номером $k$ при $A_{1}<d=(k+1) \cdot P-l_{i} \cdot R_{i}$, або до діапазону з номером $(k+1)$ при $A_{2} \geq d$. Звернемо увагу на несуттєву залежність номеру піддіапазону від величини початкового (неспотвореного) числа та на суттєву його залежність від місця та величини спотворення. Іншими словами, спотворення певної величини в певному умовному лишку призводить до переміщення будь-якого вихідного числа лише до одного із двох суміжних піддіапазонів з номерами $k$ або $(k+1)$.

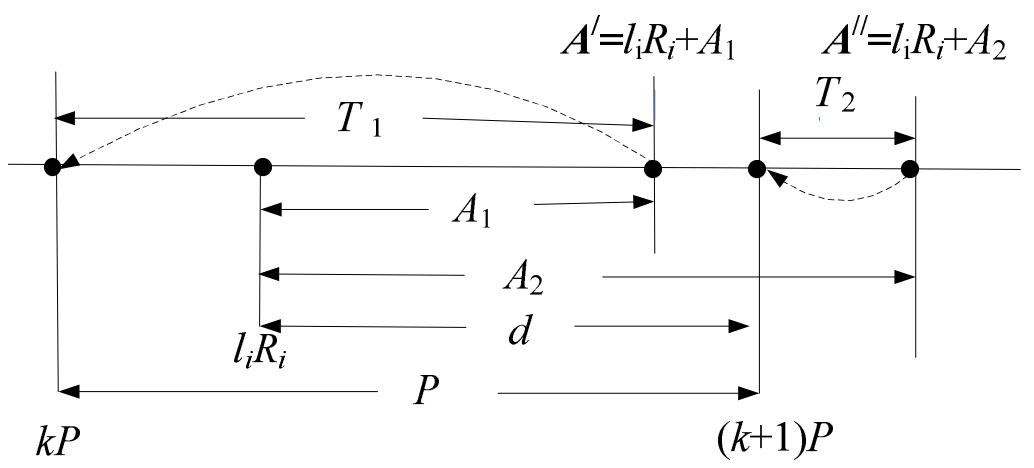

Ілюстрація процесу нулізації

Звідси робимо висновок, що визначення у будь-який спосіб величини $l_{i} \cdot R_{i}$, забезпечує визначення місця спотворення $(i)$, його величини $\Delta a_{i}=\left(l_{i} \cdot R_{i}\right) \bmod p_{i}$. Iз рисунка зрозуміло також, що номер піддіапазону $k$ нескладно визначити із очевидного співвідношення

$$
k=\left[l_{i} \cdot R_{i} / P\right],
$$

де позначка $[X]$ означає обчислення цілої частини від $X$.

Як видно із рисунку, відстань між величиною $l_{i} \cdot R_{i}$ та найближчими до неї величинами $k \cdot P$ та $(k \cdot P+1)$ завжди $\epsilon$ меншою ніж величина робочого діапазону $P$. Цей факт можна використати для визначення величини $l_{i} \cdot R_{i}$ шляхом розв'язання систем нерівнянь:

$$
\begin{gathered}
l_{i} \cdot R_{i}-k \cdot P<P, \\
(k+1) \cdot P-l_{i} \cdot R_{i}<P .
\end{gathered}
$$

Тобто, після операції нулізації та визначення $k$ і встановлення факту наявності спотворення $(\gamma \neq 0)$, рішення цих систем — знаходження вірної нерівності шляхом перебору $i$, та, відповідно $R_{i}$, і дозволяє визначити всі шукані змінні, необхідні для корегування цього спотворення: $i$ - номер спотвореної групи розрядів (спотвореного лишку), місце спотворення та $\Delta a_{i}=\left(l_{i} \cdot R_{i}\right) \bmod p_{i}$ - величина спотворення:

$$
a_{i}=\left(\tilde{a}_{i}-\Delta a_{i}\right) \bmod p_{i} .
$$


Таким чином, алгоритм виявлення факту наявності та корегування спотворень складається 3 наступних етапів.

1. Виявлення факту наявності спотворень шляхом аналізу результату нулізації величини $\gamma$ : при $\gamma \neq 0$ робиться висновок про наявність спотворення.

2. Визначення номеру піддіапазонів $k$ чи $(k+1)$, до якого, залежно від початкового значення вихідного числа $A$, попало спотворене число $\widetilde{A}$.

3. Визначення місця спотворення: $i$ - номеру спотвореної групи розрядів, а отже, спотвореного лишку $\widetilde{a}_{i}$, та величини спотворення $\Delta a_{i}=\left(l_{i} \cdot R_{i}\right) \bmod p_{i}$.

4. Корегування спотворень.

Послідовність операцій (процедур) першого етапу є відомою і додатково розглядалася вище. Найбільш зрозумілим шляхом визначення номеру піддіапазонів $k$ чи $(k+1)$ на другому етапі є реалізація операцій (процедур) з розв'язання систем нерівнянь $(2, a)$ та $(2, б)$. Розглянемо послідовність цих операцій.

Визначення номерів піддіапазонів $k$ чи $(k+1)$ на другому етапi розглянемо як продовження прикладу 2. Для цього скористаємося наведеним раніше співвідношенням $\gamma=(k P) \bmod p_{q}$. Із цього виразу номер піддіапазону $k=\left\{\gamma /\{P\}_{p_{q}}\right\}_{p_{q}}$ і для умов прикладу 2: $k=\left\{51 /\{140\}_{71}\right\}_{71}=\{51 / 69\}_{71}=10$ i, відповідно, $(k+1)=11$.

Завдання третього етаny розглянемо шляхом розв'язання систем нерівнянь $(2, a)$ та $(2, \sigma)$ щодо спотвореного числа $\widetilde{A}=11.01 .01 .0110011$, коли вже виконані операції етапів 1 та 2 внаслідок чого одержано: $\gamma \neq 0$, зроблено висновок про наявність спотворення в числі, що декодується, та можливі номери піддіапазонів розташування спотворення $k=10 \mathrm{i}(k+1)=11$.

Нагадаємо, що в цій роботі розглядаються приклади для системи числення 3 константами: величина робочого діапазону $P=4 \cdot 5 \cdot 7=140$, величина повного діапазону $R=P \cdot p_{q}=4 \cdot 5 \cdot 7 \cdot 71=9940, R_{1}=R / p_{1}=2485, R_{2}=R / p_{2}=1988, R_{3}=R / p_{3}=$ $=1420$. Тоді, окрім того, $k \cdot P=1400$, та $(k+1) \cdot P=1540$.

Для розв'язання систем нерівнянь $(2, a),(2, \sigma)$ необхідними є додаткові константи системи числення, якими є величини можливих спотворень у цій системі числення $l_{i} \cdot R_{i}$ для всіх номерів умовних основ $i$ та усіх значень номерів відповідних піддіапазонів $l_{i}$. Ці константи розраховуються в процесі розв'язання систем нерівнянь $(2, a)$ та $(2, б)$.

Розглянемо послідовність операцій при розв'язання систем нерівнянь $(2, a)$ та $(2, \sigma)$.

1. Для аналізу можливого спотворення в першій групи (умовний лишок по основі $p_{1}=4$ (6 операцій порівняння)), необхідно в міру зміни значення $l_{1}$ розрахувати:

— при $l_{1}=1: \Delta A=l_{1} \cdot R_{1}=2485$; при $l_{1}=2: \Delta A=l_{1} \cdot R_{1}=4970$; при $l_{1}=3: \Delta A=$ $=l_{1} \cdot R_{1}=7455$;

- при перевірці правильності нерівнянь $(21, a)$ та $(2, \sigma)$, оскільки $k \cdot P=1400$ і $(k+1) \cdot P=1540 €$ меншими ніж найменше $3 l_{1} \cdot R_{1}=2485$, вочевидь, робимо висновок про відсутність рішень зазначених нерівностей.

2. Для аналізу можливого спотворення в другій групі (умовний лишок по основі $p_{2}=5$ (8 операцій порівняння), необхідно в міру зміни значення $l_{2}$ розрахувати: 
— при $l_{2}=1: \Delta A=l_{2} \cdot R_{2}=1988$; при $l_{2}=2: \Delta A=l_{2} \cdot R_{2}=3976$; при $l_{2}=3: \Delta A=$ $l_{2} \cdot R_{2}=5964 ;$ при $l_{2}=4: \Delta A=\left(l_{2} \cdot R_{2}\right)=7952$;

- при перевірці правильності нерівнянь $(2, a)$ та $(2, \sigma)$, оскільки $k \cdot P=1400$ і $(k+1) \cdot P=1540 €$ меншими ніж найменше $3 l_{2} \cdot R_{2}=1988$ також робимо висновок про відсутність рішень зазначених нерівностей.

3. Для аналізу можливого спотворення в третій групі (умовний лишок по основі $p_{3}=7$ (до 12 операцій порівняння), необхідно в міру зміни значення $l_{3}$ розрахувати:

— при $l_{3}=1: \Delta A=l_{3} \cdot R_{3}=1420 ;$ при $l_{3}=2: \Delta A=l_{3} \cdot R_{3}=2840 ;$ при $l_{3}=3: \Delta a_{3}=$ $=\left(l_{3} \cdot R_{3}\right)=4260$; при $l_{3}=4: \Delta A=l_{3} \cdot R_{3}=5680$; при $l_{3}=5: \Delta A=l_{3} \cdot R_{3}=7100$; при $\left.l_{3}=6: \Delta A=l_{3} \cdot R\right)=8520$;

- при перевірці правильності нерівнянь $(2, a)$ та $(2, б)$, виявляється випадок задовольняння нерівності для $k \cdot P=1400$ при $l_{3} \cdot R_{3}=1420\left(l_{3} \cdot R_{3}-k \cdot P=\right.$ $=1420-1400=20<140)$, звідки витікає рішення про наявність спотворення третьої групи розрядів вихідного числа зазначених нерівностей.

Величина спотворення $-\Delta a_{3}=\left(l_{3} \cdot R_{3}\right) \bmod p_{3}=1420 \bmod 7=6$, а операція корегування спотворення $a_{3}=\left(\widetilde{a}_{3}-\Delta a_{3}\right) \bmod p_{3}=(1-6) \bmod 7=2=10_{2}$, що відповідає значенню цієї групи у неспотвореному числі.

Оскільки максимальна кількість операцій при розв'язанні систем нерівнянь $(2, a)$ та $(2,6)$ дорівнює $\left(p_{i}-1\right)$ для кожної із $n$ груп, то максимальна кількість операцій при розв'язанні систем нерівнянь по усім $n$ групам складе: $\left(\sum_{i=1}^{n} p_{i}-n\right)$. Отже, при великій кількості умовних основ $p_{i}$ та їхніх значних величинах тривалість третьої процедури алгоритму виявлення факту наявності та корегування спотворень може бути суттєвою. Із цього витікає висновок щодо необхідності виявлення можливостей щодо ії прискорення.

\section{Табличне корегування спотворень за резумьтатами нумізації}

Прискорення цієї процедури є можливим у разі використання однозначної функціональної пов’язаності між результатами виконання операції нулізації $\gamma$, можливими номерами суміжних піддіапазонів величиною $P-k=\left\{\gamma /\{P\}_{p_{q}}\right\}_{p_{q}}$ (чи, можливо $(k+1)$, що залежить від величини неспотвореного числа, яке контролюється), та величиною спотворення вихідного числа $E=\left(l_{i} \cdot R_{i}\right)$, а отже, величиною спотворення $\Delta a_{i}$ та номером $i$ спотвореної групи у числі, яке контролюється.

3 викладеного робимо висновок, що при застосуванні нулізації для встановлення факту наявності спотворень $(\gamma \neq 0)$ для будь-якого спотворення $\Delta A_{i}=l_{i} \cdot R_{i}$ та прискорення процедури із визначення місця та величини спотворень доцільно заздалегідь визначити та створити таблицю відповідності між результатом нулізації $\gamma$ (чи парою суміжних номерів піддіапазонів $k,(k+1))$ та $\Delta a_{i}, l_{i}$. Зрозуміло, що така таблиця формується для умов застосування певної системи умовних лишків, тобто певного набору основ такої системи. Звернемо увагу на те, що для кожного 
iз можливих спотворень $\Delta a_{i}$ взаємно пов'язані величини $\gamma, k$, та, відповідно $(k+$ $+1)$, можуть бути визначеними із уже застосованих чи зрозумілих співвідношень:

$$
\Delta a_{i}=\left(l_{i} \cdot R_{i}\right) \bmod p_{i}, k=\left[l_{i} \cdot R_{i} / P\right], \gamma=\{k \cdot P\}_{p_{q}} .
$$

Формування такої таблиці розглянемо на прикладі вже розглянутої у попередніх прикладах системи умовних лишків, що дозволяє виявляти та виправляти спотворення в дворозрядних групах із $p_{1}=4, p_{2}=5, p_{3}=7$ та $p_{q}=71$ та ії основними константами: величина робочого діапазону $P=4 \cdot 5 \cdot 7=140$, величина повного діапазону $R=9940, R_{1}=R / p_{1}=2485, R_{2}=R / p_{2}=1988, R_{3}=R / p_{3}=1420$.

Знайдемо співвідношення між величинами можливих спотворень і номерами піддіапазонів, до яких може бути «переміщеним» унаслідок цих спотворень вихідний інформаційний об'єкт у такій системі числення:

— для $l_{1}=1: \Delta a_{1}=\left(l_{1} \cdot R_{1}\right) \bmod 4=2485 \bmod 4=1 ; k=[2485 / 140]=17$, $\gamma=\{17 \cdot 140\}_{71}=\{2380\}_{71}=37 ;(k+1)=18 ; \gamma=\{18 \cdot 140\}_{71}=\{2520\}_{71}=35$; для $l_{1}=2$ : $\Delta a_{1}=\left(l_{1} \cdot R_{1}\right) \bmod 4=4970 \bmod 4=2, k=[4970 / 140]=35, \gamma=\{35 \cdot 140\}_{71}=$ $=\{4900\}_{71}=1 ;(k+1)=36, \gamma=\{36 \cdot 140\}_{71}=\{5040\}_{71}=70 ;$ для $l_{1}=3: \Delta a_{1}=\left(l_{1} \cdot R_{1}\right)$ $\bmod 4=7455 \bmod 4=3, k=[7455 / 140]=53, \gamma=\{53 \cdot 140\}_{71}=\{7420\}_{71}=36 ;(k+1)=$ $=54, \gamma=\{54 \cdot 140\}_{71}=\{7560\}_{71}=34$;

— для $l_{2}=1: \Delta a_{2}=\left(l_{2} \cdot R_{2}\right) \bmod 5=1988 \bmod 5=3, k=[1988 / 140]=14$, $\gamma=\{14 \cdot 140\}_{71}=\{1960\}_{71}=43 ;(k+1)=15, \gamma=\{15 \cdot 140\}_{71}=\{2100\}_{71}=41 ;$ для $l_{2}=2$ : $\Delta a_{2}=\left(l_{2} \cdot R_{2}\right) \bmod 5=3976 \bmod 5=1, k=[3976 / 140]=28, \gamma=\{28 \cdot 140\}_{71}=$ $=\{3920\}_{71}=15 ;(k+1)=29, \gamma=\{29 \cdot 140\}_{71}=\{4060\}_{71}=13$; для $l_{2}=3: \Delta a_{2}=\left(l_{2} \cdot R_{2}\right)$ $\bmod 5=5964 \bmod 5=4, k=[5964 / 140]=42, \gamma=\{42 \cdot 140\}_{71}=\{5880\}_{71}=58 ;(k+1)=$ $=43, \gamma=\{43 \cdot 140\}_{71}=\{6020\}_{71}=56$; для $l_{2}=4: \Delta a_{2}=\left(l_{2} \cdot R_{2}\right) \bmod 5=7952 \bmod 5=2$, $k=[7952 / 140]=56, \gamma=\{56 \cdot 140\}_{71}=\{7840\}_{71}=30 ;(k+1)=57, \gamma=\{57 \cdot 140\}_{71}=$ $=\{7980\}_{71}=28$;

— для $l_{3}=1: \Delta a_{3}=\left(l_{3} \cdot R_{3}\right) \bmod 7=1420 \bmod 7=6, k=[1420 / 140]=10$, $\gamma=\{10 \cdot 140\}_{71}=\{1400\}_{71}=51 ;(k+1)=11, \gamma=\{11 \cdot 140\}_{71}=\{1540\}_{71}=49$; для $l_{3}=2$ : $\Delta a_{3}=\left(l_{3} \cdot R_{3}\right) \bmod 7=2840 \bmod 7=5, k=[2840 / 140]=20, \gamma=\{20 \cdot 140\}_{71}=$ $=\{2800\}_{71}=31 ;(k+1)=21, \gamma=\{21 \cdot 140\}_{71}=\{2940\}_{71}=29 ;$ для $l_{3}=3: \Delta a_{3}=\left(l_{3} \cdot R_{3}\right)$ $\bmod 7=4260 \bmod 7=4, k=[4260 / 140]=30, \gamma=\{30 \cdot 140\}_{71}=\{4200\}_{71}=11 ;(k+1)=$ $=31, \gamma=\{31 \cdot 140\}_{71}=\{4340\}_{71}=9$; для $l_{3}=4: \Delta a_{3}=\left(l_{3} \cdot R_{3}\right) \bmod 7=5680 \bmod 7=3$, $k=[5680 / 140]=40, \gamma=\{40 \cdot 140\}_{71}=\{5600\}_{71}=62 ;(k+1)=41, \gamma=\{41 \cdot 140\}_{71}=$ $=\{5740\}_{71}=60 ;$ для $l_{3}=5: \Delta a_{3}=\left(l_{3} \cdot R_{3}\right) \bmod 7=7100 \bmod 7=2, k=[7100 / 140]=$ $=50, \gamma=\{50 \cdot 140\}_{71}=\{7000\}_{71}=42 ;(k+1)=51, \gamma=\{51 \cdot 140\}_{71}=\{7140\}_{71}=40$; для $l_{3}=6: \Delta a_{3}=\left(l_{3} \cdot R_{3}\right) \bmod 7=8520 \bmod 7=1, k=[8520 / 140]=60, \gamma=\{60 \cdot 140\}_{71}=$ $=\{8400\}_{71}=22 ;(k+1)=61, \gamma=\{61 \cdot 140\}_{71}=\{8540\}_{71}=20$. 
Звернемо увагу, що такі розрахунки дійсно можуть бути зробленими заздалегідь, оскільки їхні результати не є залежними від можливих величин чисел, цілісність яких слід перевірити та, в разі потреби, відновити. Тому їх можна представити таблицею наведеного нижче вмісту.

У таблиці у першому рядку (вхід у таблицю) наводиться результат нулізації $\gamma$, у другому - номер групи спотворених розрядів $i$, у третьому - величина спотворення $\Delta a_{i}$. Тоді при контролі та поновленні цілісності, одержавши внаслідок операції нулізації лишок по контрольній основі $\gamma$, можна зчитати $з$ таблиці номер спотвореної групи $i$ та величину спотворення $\Delta a_{i}$. Таким чином, задачі третього етапу вирішуються, по суті, за одну операцію звернення до таблиці.

Для прикладу 1 із таблиці визначаємо, що при $\gamma=51$ виявлено наявність спотворення у третій групі величиною $\Delta a_{3}=6_{10}=110_{2}$, що дійсно мало місце. Отже задачі третього етапу - визначення місця спотворення: номеру $i$ спотвореної групи розрядів, а отже, спотвореного лишку $\tilde{a}_{i}$, та величина його спотворення $\Delta a_{i}=\left(l_{i} \cdot R_{i}\right) \bmod p_{i} \in$ розв'язаними.

Тоді, одержавши місце виникнення $i$ та величину спотворення $\Delta a_{i}$, на четвертому етапі можна також за одну модульну операџію здійснити корегування спотворення (див. вираз (1)):

$$
a_{i}=\left(\tilde{a}_{i}-\Delta a_{i}\right) \bmod p_{i} .
$$

Для попередніх прикладів:

\begin{tabular}{c|c|c|c|c|c|c|c|c|c|c|c|c|c|c}
\hline \hline$\gamma$ & $\mathbf{0}$ & $\mathbf{1}$ & $\mathbf{2}$ & $\mathbf{3}$ & $\mathbf{4}$ & $\mathbf{5}$ & $\mathbf{6}$ & $\mathbf{7}$ & $\mathbf{8}$ & $\mathbf{9}$ & $\mathbf{1 0}$ & $\mathbf{1 1}$ & $\mathbf{1 2}$ & $\mathbf{1 3}$ \\
\hline \hline$i$ & & 1 & & & & & & & & 3 & & 3 & & 2 \\
\hline$\Delta a_{i}$ & & 2 & & & & & & & & 4 & & 4 & & 1 \\
\hline$\gamma$ & $\mathbf{1 4}$ & $\mathbf{1 5}$ & $\mathbf{1 6}$ & $\mathbf{1 7}$ & $\mathbf{1 8}$ & $\mathbf{1 9}$ & $\mathbf{2 0}$ & $\mathbf{2 1}$ & $\mathbf{2 2}$ & $\mathbf{2 3}$ & $\mathbf{2 4}$ & $\mathbf{2 5}$ & $\mathbf{2 6}$ & $\mathbf{2 7}$ \\
\hline$i$ & & 2 & & & & & 3 & & 3 & & & & & \\
\hline$\Delta a_{i}$ & & 1 & & & & & 1 & & 1 & & & & & \\
\hline$\gamma$ & $\mathbf{2 8}$ & $\mathbf{2 9}$ & $\mathbf{3 0}$ & $\mathbf{3 1}$ & $\mathbf{3 2}$ & $\mathbf{3 3}$ & $\mathbf{3 4}$ & $\mathbf{3 5}$ & $\mathbf{3 6}$ & $\mathbf{3 7}$ & $\mathbf{3 8}$ & $\mathbf{3 9}$ & $\mathbf{4 0}$ & $\mathbf{4 1}$ \\
\hline$i$ & 2 & 3 & 2 & 3 & & & 1 & 1 & 1 & 1 & & & 3 & 2 \\
\hline$\Delta a_{i}$ & 2 & 5 & 2 & 5 & & & 3 & 1 & 3 & 1 & & & 2 & 3 \\
\hline$\gamma$ & $\mathbf{4 2}$ & $\mathbf{4 3}$ & $\mathbf{4 4}$ & $\mathbf{4 5}$ & $\mathbf{4 6}$ & $\mathbf{4 7}$ & $\mathbf{4 8}$ & $\mathbf{4 9}$ & $\mathbf{5 0}$ & $\mathbf{5 1}$ & $\mathbf{5 2}$ & $\mathbf{5 3}$ & $\mathbf{5 4}$ & $\mathbf{5 5}$ \\
\hline$i$ & 3 & 1 & & & & & & 3 & & 3 & & & & \\
\hline$\Delta a_{i}$ & 2 & 3 & & & & & & 6 & & 6 & & & & \\
\hline$\gamma$ & $\mathbf{5 6}$ & $\mathbf{5 7}$ & $\mathbf{5 8}$ & $\mathbf{5 9}$ & $\mathbf{6 0}$ & $\mathbf{6 1}$ & $\mathbf{6 2}$ & $\mathbf{6 3}$ & $\mathbf{6 4}$ & $\mathbf{6 5}$ & $\mathbf{6 6}$ & $\mathbf{6 7}$ & $\mathbf{6 8}$ & $\mathbf{6 9}$ \\
\hline$i$ & 2 & & 2 & & 3 & & 3 & & & & & & & \\
\hline$\Delta a_{\mathrm{i}}$ & 4 & & 4 & & 3 & & 3 & & & & & & & \\
\hline$\gamma$ & $\mathbf{7 0}$ & & & & & & & & & & & & & \\
\hline$i$ & 1 & & & & & & & & & & & & & \\
\hline$\Delta a_{i}$ & 2 & & & & & & & & & & & & & \\
\hline \hline
\end{tabular}




$$
a_{i}=\left(\widetilde{a}_{3}-\Delta a_{3}\right) \bmod p_{3}=(001-110) \bmod 7=10_{2} .
$$

Неважко упевнитися в правильності виконаного корегування.

\section{Висновок}

Запропоновано швидкодіючий алгоритм декодування для коду умовних лишків, який дозволяє на основі процедури нулізації за одну табличну операцію визначити як місце, так і величину спотворення і здійснити, за одну модульну операцію корекцію виявлених спотворень.

1. Василенко В.С. Целостность и доступность информационных объектов (монография) / В.С. Василенко, О.Я. Матов. — Saarbrucken, Deutschland: LAMBERT Academic Publishing, 2013. 95 с. - ISBN 978-3-659-47333-3.

2. Василенко В.С. Код условных вычетов (монография) / В.С. Василенко. - Saarbrucken, Deutschland: LAMBERT Academic Publishing, 2013. - 129 c. — ISBN 978-3-659-48203-8.

3. Матов О.Я. Теорія інформації та кодування (монографія) / О.Я. Матов, В.С. Василенко // Х.: Експрес-книга, 2014. - 440 с. — ISBN 978-966-02-7096-1.

4. Матов О.Я. Контроль та поновлення цілісності на основі алгоритму нулізації в коді умовних лишків / О.Я. Матов, В.С. Василенко, М.Ю. Василенко // Реєстрація, зберігання і оброб. даних. - 2011. - Т. 13, № 3. - С. 72-81. 